07,13

\title{
Физико-механические свойства и микромеханизмы локального деформирования материалов с различной зависимостью твердости от глубины отпечатка
}

\author{
() Ю.И. Головин ${ }^{1}$, А.И. Тюрин ${ }^{1}$, Э.Г. Асланян ${ }^{2}$, Т.С. Пирожкова ${ }^{1}$, В.М. Васюков ${ }^{1}$ \\ ${ }^{1}$ Научно-исследовательский институт „Нанотехнологии и наноматериалы“ \\ Тамбовского государственного университета им. Г.Р. Державина, \\ Тамбов, Россия \\ ${ }^{2}$ Всероссийский научно-исследовательский институт фризико-технических и радиотехнических измерений, \\ Менделеево, Россия \\ E-mail: golovin@tsu.tmb.ru
}

(Поступила в Редакцию 13 декабря 2016 г.

В окончательной редакции 20 марта 2017 г.)

\begin{abstract}
Методами микро- и наноиндентирования в широком диапазоне глубин отпечатка $h$ (от десятков нанометров до нескольких десятков микрометров) изучены размерные эффекты в твердости нескольких классов материалов: ионных и ковалентных монокристаллов (сапфира, кремния, фторида лития); металлов (монокристаллического Al, поликристаллических $\mathrm{Cu}, \mathrm{Ni}, \mathrm{Nb}$ ); керамик (высокопрочной наноструктурированной TZP-керамики на основе природного минерала диоксида циркония - бадделеита); аморфных материалов (плавленого кварца); полимеров (поликарбоната и политетрафторэтилена). Показано, что некоторые из них демонстрируют сильные размерные эффекты в твердости, другие - слабые, а третьи - вовсе их отсутствие. Проведен термоактивационный анализ и определены активационные и энергетические характеристики процессов локального деформирования под индентором, которые сопоставлены с доминирующими микромеханизмами пластичности исследованных материалов на разных стадиях формирования отпечатка, а также с особенностями размерных эффектов. Выявлены материалы, имеющие низкие значения коэффициента вариации твердости, согласующиеся с требованиями стандартов измерения нанотвердости ISO 14577 и ГОСТ P 8.748-2011. В установленных диапазонах нагрузок эти материалы являются хорошими кандидатами для использования в качестве эталонов, призванных обеспечивать единство измерений твердости для нано- и микродиапазонов, а также для проведения калибровок и испытаний наноиндентометров.

Экспериментальное исследование размерных эффектов при наноиндентировании выполнено при поддержке гранта Российского научного фонда (проект № 15-19-00181). Исследование физико-механических свойств TZP-керамики, а также обоснование методов калибровки и выбора материалов для эталонных образцов выполнены при поддержке гранта Российского научного фонда (проект № 16-19-10405).
\end{abstract}

DOI: 10.21883/FTT.2017.09.44851.443

\section{1. Введение}

Современные нанотехнологии позволяют создавать изделия и отдельные компоненты с микронными, субмикронными и нанометровыми характерными размерами. В частности, получили распространение миниатюрные микро-/наноэлектромеханические системы, сенсоры, актуаторы, многослойные структуры [1-4], тонкие пленки, покрытия [5] и др. При их проектировании, изготовлении и эксплуатации необходимо учитывать, что физико-механические свойства традиционных и, особенно, новых, наноструктурированных материалов в субмикронных и нанообъемах, тонких пленках и приповерхностных слоях могут сильно отличаться от макроскопических свойств, приводимых в инженерных справочниках. Такое различие принято квалифицировать как размерные эффекты (size effects, SE) [1-4].

В качестве характерного размера $R^{*}$, определяющего границу перехода между макроскопическими и наноразмерными свойствами, могут выступать как внешние геометрические размеры образца, радиус контактного пятна при локальном деформировании, так и характерные размеры микроструктуры (размеры фаз, зерен, пор, дислокационных скоплений, двойников, толщина слоев/пленок и др.) [6-20]. С точки зрения чувствительности нано- и микромеханических свойств к величине $R^{*}$ все материалы можно условно разделить на два класса: имеющие SE [4,6-12,17-19] и не демонстрирующие таковых (по крайней мере, в диапазоне $R^{*}$ от единиц нанометров до многих десятков микрометров) $[4,12,15,16,21,22]$. Атомные механизмы столь различного поведения не вполне ясны.

Известно, что материалы, в которых проявляются SE в физико-механических свойствах, деформируются в макрообъемах главным образом посредством зарождения и движения дислокаций, двойников, зернограничного проскальзывания и других многоатомных механизмов [4,6,7,17-19,23-33]. Что касается материалов, имеющих размерно-независимые механические свойства, то в литературе практически не обсуждаются вопросы, 
связанные с причинами отсутствия в них SE. Пролить свет на природу размерных зависимостей или их отсутствия в локальных механических свойствах, в частности, при индентировании (indentation size effect, ISE) может проведение их систематических экспериментальных исследований, а также выявление доминирующих атомных механизмов деформации, которая протекает под индентором, внедряющимся на различную глубину и, следовательно, вовлекающим в пластическую деформацию сильно различающиеся объемы материала. В современных наноиндентометрах имеется возможность непрерывно регистрировать силу вдавливания и глубину погружения индентора в материал в диапазоне от долей нанометров до десятков микрометров. Это позволяет осуществлять размерное сканирование свойств материала в процессе одного испытания, при котором происходит изменение пластически деформированного объема более чем на 12 порядков величины!

Однако для подробного анализа закономерностей и природы ISE необходимо сначала получить надежные экспериментальные данные о локальных механических свойствах, номенклатуре и динамике структурных дефектов - потенциальных носителей пластической деформации, которые образуются под индентором, в как можно более широком диапазоне размеров и объема зоны деформирования. Следует отметить, что современные наноиндентометры обладают высокой чувствительностью к индивидуальным характеристикам вершины индентора, параметрам коррекции и настроек инструмента, а также методам обработки „сырых“ (первичных) данных и извлечения из них механических характеристик материала. Это часто приводит к артефактам и рассогласованию результатов, полученных разными авторами. Поэтому предметом особой заботы в работе были тщательные калибровки используемых приборов и накопление большой статистики измерений в одних и тех же условиях (до 300 индивидуальных измерений на одну точку).

Целями настоящей работы было:

- получение систематических, статистически достоверных данных о твердости материалов различных классов, имеющих размерно-зависимые и размернонезависимые свойства в наношкале в широком диапазоне силы вдавливания $P$, перекрывающем пять порядков величины (от $10 \mu \mathrm{N}$ до $1 \mathrm{~N}$ ) и глубины погружения индентора $h$ (от единиц нанометров до десятков микрометров);

- проведение термоактивационного анализа и выявление доминирующих атомных механизмов локального деформирования материала под индентором на разных стадиях его погружения, т.е. при разном характерном размере зоны пластической деформации, за который принималась глубина отпечатка $h$;

- установление взаимосвязи между ISE и атомными механизмами локального деформирования ряда репрезентативных представителей материалов различных классов;
- обоснование выбора материалов, которые можно было бы использовать для калибровки наноиндентометров в широком диапазоне твердости и упругости по стандартам ГОСТ Р 8.748-2011 [34] и ISO 14577 [35].

\section{2. Материалы и методы исследований}

Для достижения поставленных целей набор материалов для проведения исследований должен перекрывать широкий диапазон упругопластических свойств. Необходимо также, чтобы сами материалы отвечали ряду требований:

1) среди исследуемых должны быть материалы, имеющие как размерно-зависимые, так и размернонезависимые механические свойства в нано- и микрошкале;

2) материалы должны обладать высокой степенью однородности (постоянством от точки к точке) локальных механических свойств;

3) иметь различные атомные механизмы локального деформирования;

4) не создавать градиентной структуры вблизи поверхности, в частности, не образовывать приповерхностных упрочненных или разупрочненных слоев;

5) давать возможность подготовить неупрочненную поверхность со среднеквадратической шероховатостью не более нескольких нанометров;

6) иметь стабильные приповерхностные свойства на больших промежутках времени (не деградировать, не окисляться, иметь низкое газопоглощение и т. п.).

С учетом этих требований и имеющихся литературных данных о механических свойствах был проведен предварительный отбор материалов различных классов для проведения тестовых испытаний. Для исследования были выбраны репрезентативные представители материалов различных классов: мягкие металлы (монокристаллический $\mathrm{Al}$, поликристаллические $\mathrm{Cu}, \mathrm{Nb}, \mathrm{Ni}$ ), жесткие ионные и ковалентные монокристаллы (сапфир, кремний, фторид лития), полимеры (поликарбонат и политетрафторэтилен), наноструктурированная ТZР-керамика с размером зерен $\sim 130 \mathrm{~nm}$ на основе бадделеита природного диоксида циркония - и аморфный материал (плавленый кварц). В совокупности эти материалы охватывают широкий диапазон упругих и прочностных свойств: около трех порядков по твердости индентирования $H_{\text {Iт }}$ и более двух порядков по модулю Юнга $E$. На рис. 1 их свойства представлены в обычно используемых для таких случаев координатах $E / H_{\mathrm{IT}}^{0.5}$ (характеризует

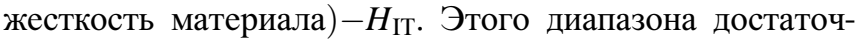
но для проведения калибровки наноиндентометров в интервале $P$ от нескольких десятков микроньютонов до $1 \mathrm{~N}$ и $h$ от $\sim 10 \mathrm{~nm}$ до десятков микрометров, что полностью соответствует выполнению требований стандартов [34,35] для нано- и микродиапазонов.

Измерение твердости на микро- и наноуровне проводилось на нанотрибоиндентометре (TriboIndenter TI-950) 


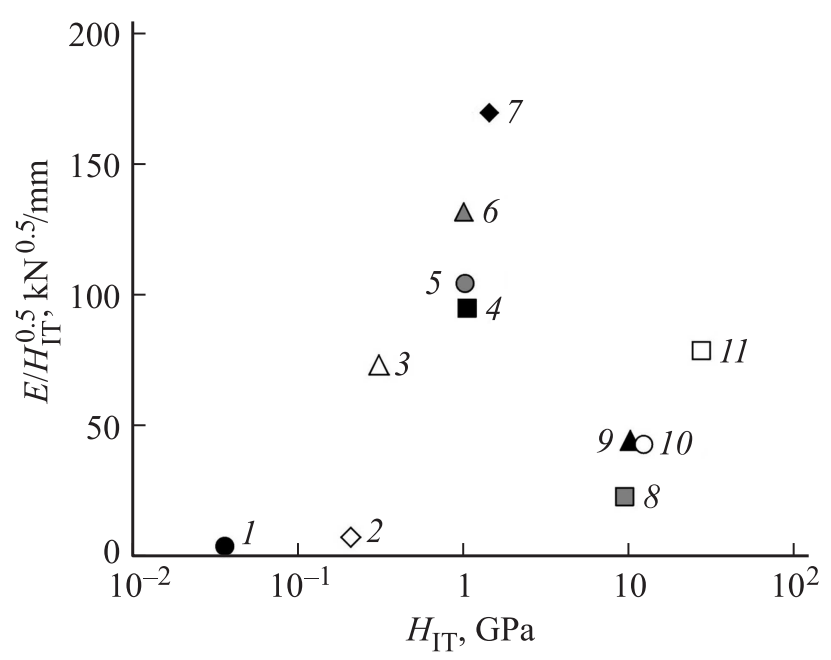

Рис. 1. Механические свойства исследованных материалов. 1 - политетрафторэтилен, 2 - поликарбонат, 3 - $\mathrm{Al}$, $4-\mathrm{LiF}, 5-\mathrm{Nb}, 6-\mathrm{Cu}, 7-\mathrm{Ni}, 8-$ плавленый кварц, $9-\mathrm{Si}, 10$ - ТZР-керамика, $11-$ сапфир.

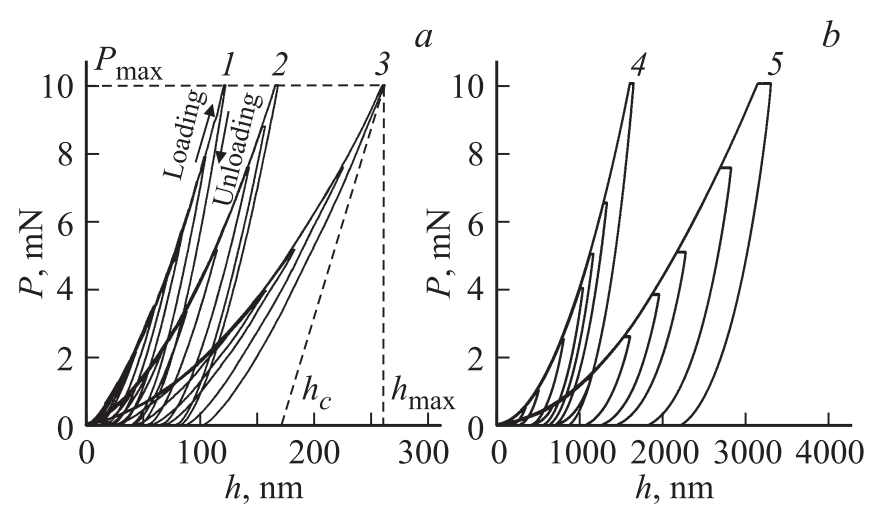

Рис. 2. Типичные $P-h$-диаграммы нагружения-разгрузки при нарастающей максимальной силе вдавливания $P_{\max }$ для ряда исследованных материалов. $a$ - сапфир (1), ТZР-керамика (2), плавленый кварц (3); $b$ - поликарбонат (4), политетрафторэтилен (5).

фирмы Hysitron (USA) в диапазоне нормальной силы от $10 \mu \mathrm{N}$ до $1 \mathrm{~N}$, прикладываемой к индентору. Для испытаний в микро- и макрошкале использовались твердомеры G200 фирмы MTS (USA), Duramin A300 фирмы Struers (Denmark) и TNi-micro (собственной разработки). Значения $E, H_{\mathrm{IT}}=P_{\max } / A_{p}\left(h_{c}\right)$ и твердости по Мартенсу - $H M=P_{\max } / A_{s}\left(h_{\max }\right)$ - определялись по методикам Оливера-Фарра $[15,16,34,35]$ и Мартенса [35] из характерных $P$-h-диаграмм (рис. 2) в соответствии со стандартами [34,35]. Здесь $P_{\max }-$ максимальная нагрузка, приложенная к индентору; $A_{p}\left(h_{c}\right)$ - площадь проекции отпечатка на поверхность образца, определяемая по $P$-h-диаграмме в зависимости от глубины пластического отпечатка $h_{c} ; A_{s}\left(h_{\max }\right)$ - площадь поверхности внедряющегося индентора на расстоянии $h_{\max }$ от его вершины; $h_{\max }$ - максимальная глубина отпечатка.

\section{3. Результаты и их обсуждение}

Зависимости $H_{\text {IT }}$ и $H M$ от $h_{c}$ и $h_{\text {max }}$ для исследованных материалов приведены на рис. 3 и 4. Каждая точка на кривых была получена усреднением результатов от 100 до 300 индивидуальных измерений, проведенных в одинаковых условиях на независимых отпечатках на одном образце.

Для исключения ошибок в измерении $E$ и $H$ в наношкале на каждом приборе предварительно проводилась серия калибровочных экспериментов на одном и том же образце плавленого кварца. Этот материал традиционно используется для калибровки наноиндентометров, поскольку достоверно известно, что у него отсутствуют размерные эффекты в $H_{\text {IT }}$ и $E$ при тестировании, по крайней мере в диапазоне $h$ от единиц до тысяч нанометров (при условии отсутствия трещин вблизи отпечатка). Из результатов, приведенных на рис. $3, a$, следует, что применяемые в работе методы обработки первичных данных и настройки инструментов обеспечивают неизменность измеряемых величин $H_{\text {IT }}$ и $E$ для плавленого кварца: $H_{\mathrm{IT}}=9.2 \pm 0.1 \mathrm{GPa}, E=69.6 \pm 0.9 \mathrm{GPa}$ при изменении $h_{c}$ от 20 до $170 \mathrm{~nm}$. По абсолютной величине эти значения совпадают с литературными данными, что дает основание полагать корректными последующие
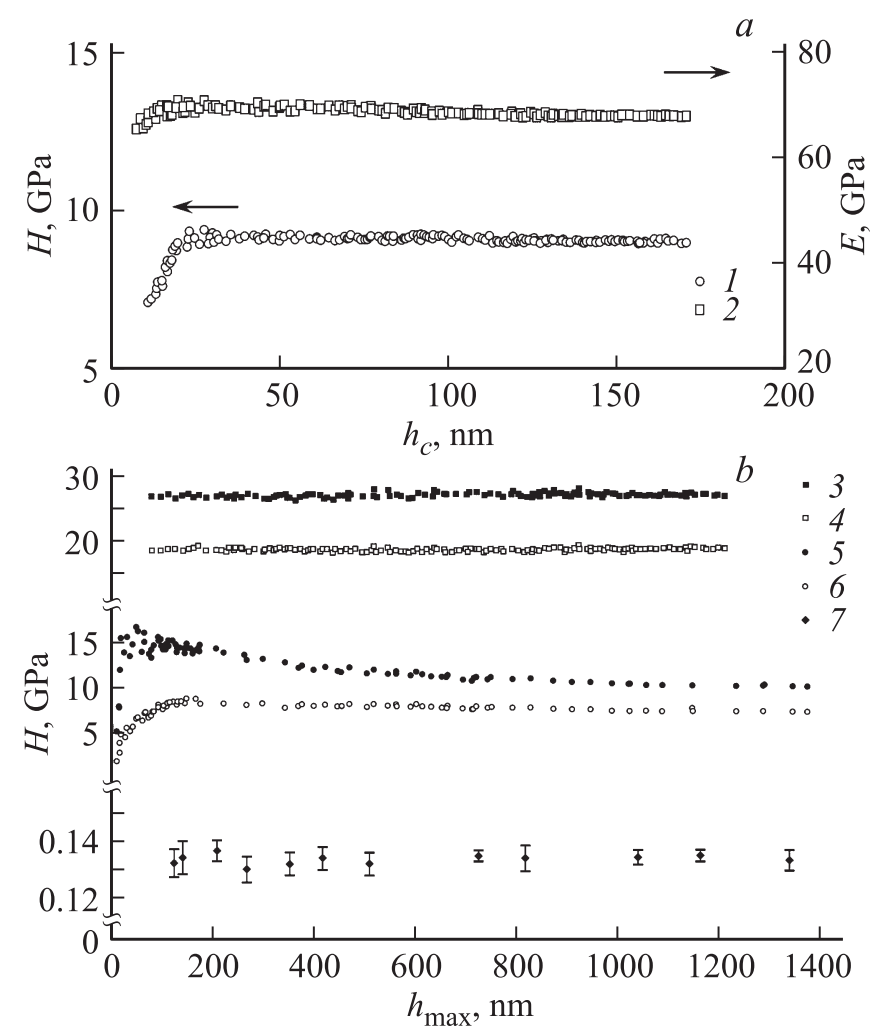

Рис. 3. Зависимости $E=f\left(h_{c}\right), H_{\mathrm{IT}}=f\left(h_{c}\right), H_{\mathrm{IT}}=f\left(h_{\max }\right)$ и $H M=f\left(h_{\max }\right)$ для ряда исследованных материалов. $a-H_{\mathrm{IT}}(1)$ и $E(2)$ для плавленого кварца; $b-H_{\mathrm{IT}}(3)$ и $H M(4)$ для сапфира, $H_{\text {IT }}(5)$ и $H M(6)$ для TZР-керамики, $H M$ для поликарбоната (7). 

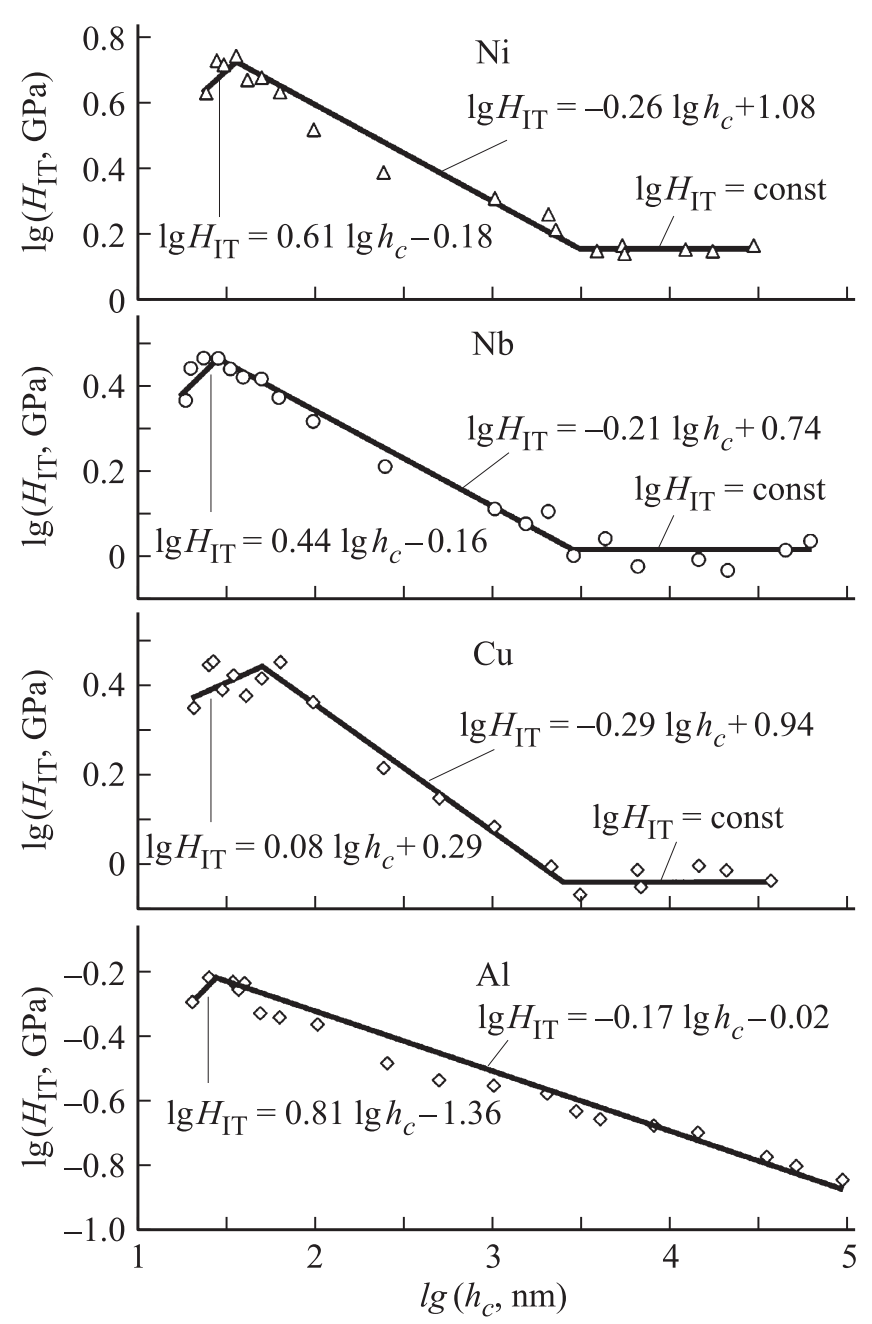

Рис. 4. Зависимости твердости индентирования $H_{\mathrm{IT}}$ исследованных материалов с наиболее ярко выраженным ISE от глубины пластического отпечатка $h_{c}$.

определения твердости и модуля Юнга и в других материалах при $h>20 \mathrm{~nm}$.

Анализ зависимостей твердости от глубины отпечатка для других исследованных материалов (рис. 3, $b$ и 4) показывает, что твердость поликарбоната и сапфира, как и плавленого кварца, не зависит от $P$ и $h$, оставаясь практически постоянной в диапазоне глубин отпечатка от нескольких десятков нанометров до нескольких микрометров. Заметим, что помимо всего прочего (см. делее) эти результаты также свидетельствуют о корректности применяемых методик. Другая группа материалов (ТZP-керамика, Si, LiF, политетрафторэтилен и др.) демонстрирует слабую размерную зависимость твердости, проявляющуюся в уменьшении ее величины с ростом глубины отпечатка в диапазоне от $100 \mathrm{~nm}$ до нескольких десятков микрометров, а также еще большее уменьшение твердости с уменьшением нагрузки и глубины отпечатка в область $h<100 \mathrm{~nm}$.

Наиболее ярко ISE проявляется в исследованных металлах (Al, $\mathrm{Cu}, \mathrm{Nb}, \mathrm{Ni})$, у которых на зависимостях $\lg H_{\mathrm{IT}}\left(\lg h_{c}\right)$ можно выделить несколько прямолинейных участков, имеющих различные коэффициенты наклона $n$ (рис. 4). Так, например, для $\mathrm{Cu}, \mathrm{Nb}$ и $\mathrm{Ni}$ ISE проявляется вплоть до глубины в несколько микрометров, вслед за которой начинается область с $H=$ const. Для Al участок с $n=0.17$ простирается по $h_{c}$ более чем на три порядка величины (от $30 \mathrm{~nm}$ и по меньшей мере до $90 \mu \mathrm{m}$ ), и даже при такой глубине еще не достигается состояние с $H_{\mathrm{IT}}=$ const.

Отсутствие на зависимостях $H_{\mathrm{IT}}=f\left(h_{c}\right)$ для ряда исследованных материалов (плавленый кварц, поликарбонат и сапфир) характерных наклонов и перегибов, выявленных для $\mathrm{Al}, \mathrm{Cu}, \mathrm{Nb}$ и $\mathrm{Ni}$ (рис. 4), означает по меньшей мере следующее: а) отсутствие градиента свойств в приповерхностном слое, b) неизменность действующего механизма деформации и независимость его от размеров пластически деформированной зоны.

Обычно полагают, что в области $R^{*}$ от $100 \mathrm{~nm}$ до $10 \mu \mathrm{m}$ определяющий вклад в возможные SE в макрообразцах могут вносить характерные размеры внутренней структуры (средний размер зерен в поликристаллах, ячеек в дислокационной структуре, толщина пленки или период сверхрешетки мультислойного покрытия и др.) $[2,4,11,12,36-38]$.

Однако при локальном деформировании роль масштабирующего фактора могут играть и другие параметры (угол при вершине индентора, радиус закругления в его кончике, размер контактного пятна, параметры шероховатости поверхности, радиус свободной поверхности образца в нитевидных кристаллах и др.). Обобщая, можно отметить, что SE в этих условиях могут возникать тогда, когда геометрические размеры локально деформированной области или расстояния до свободных или внутренних границ становятся сопоставимыми с корреляционным радиусом некого атомарного процесса, реализующего пластическое течение. В качестве такого радиуса могут выступать размеры носителя деформации, длина его свободного пробега, радиус его взаимодействия с другими несовершенствами структуры и др. Традиционные теории пластичности не содержат масштабной шкалы и соответственно не могут объяснить происхождение ISE в условиях локальной деформации.

Для описания экспериментально наблюдаемых ISE обычно используют эмпирическое соотношение типа Холла-Петча: $H=H_{m}+a h^{-m}$ (здесь $H_{m}$ - макроскопическое значение твердости при $h \geq 1 \mathrm{~mm}, a-$ коэффициент пропорциональности, $m=0.5)$. Его выполнимость при индентировании наблюдалась в ряде работ $[39,40]$, но показатель степени $m$ при $h$ редко бывает в точности равен 0.5 даже на небольших интервалах $h$, что хорошо видно, например, из наших результатов на рис. 4 .

Наиболее популярным способом интерпретации природы ISE в монокристаллах является привлечение концепции геометрически необходимых дислокаций $[6,36,41]$. С уменьшением $h$ их плотность $\rho$ растет как $h^{-1}$, что вызывает локальное упрочнение материала под индентором. Однако при $h<50-100 \mathrm{~nm}$ 
расчетная величина $\rho$, следующая из этой модели, становится нереалистично большой $\left(>10^{16} \mathrm{~m}^{-2}\right)$. Авторы работ $[6,7,42-44]$ объясняют возникновение ISE в микрообласти уменьшением размера зоны деформирования до некоторого характерного размера микроструктуры. В общем случае возможны и другие причины возникновения ISE в твердости. Так, например, одновременное действие нескольких более сложных механизмов локального деформирования (диффузионнодислокационных, дислокационно-дисклинационных, проскальзывания и поворота зерен и др. $[37,45])$ или смена доминирующих механизмов (например, недислокационных на дислокационные) [38,46-52], действующих на разных этапах формирования отпечатка, могут приводить к немонотонному изменению величины твердости с ростом глубины отпечатка и определять ISE.

Однако при этом практически не рассматриваются и не обсуждаются причины некоторых особенностей и различий в зависимости твердости от глубины отпечатка при индентировании материалов различных классов. Так, например, часто наблюдается отклонение величины наклона в зависимостях $\lg H_{\mathrm{IT}}=f\left(\lg h_{c}\right)$ от $m=0.5$ в соотношении Холла-Петча; падение $H_{\text {IT }}$ с уменьшением $h_{c}$ в области $\lesssim 50 \mathrm{~nm}$ для ряда ГЦК-металлов (рис. 4); полное отсутствие ISE при индентировании плавленого кварца и других аморфных материалов или очень маленькое значение $m(\ll 0.5)$. Следовательно, для объяснения такого поведения твердости необходимо рассмотреть и другие возможные механизмы локального деформирования материала под индентором, особенно при $h_{c} \ll 100 \mathrm{~nm}$.

Некоторый свет на причины наличия или отсутствия ISE могут пролить термоактивационный анализ, определение энергетических параметров процесса локального деформирования и выявление номенклатуры структурных дефектов, обусловливающих процесс формирования отпечатка. По меньшей мере они позволяют исключить из рассмотрения некоторые механизмы, не удовлетворяющие очевидным энергетическим и кинетическим соотношениям. Наиболее информативной при этом является величина $\gamma$ в выражении

$$
\hat{\varepsilon}=\hat{\varepsilon}_{0} \exp \left[-\left(U_{a}-\gamma \sigma\right) / k T\right],
$$

следующем из известной формулы Журкова [53,54].

В (1) $\varepsilon=(d h / d t) h-$ мгновенное значение скорости относительной деформации, $\sigma-$ мгновенное значение среднего контактного давления под индентором, $U_{a}-$ энергия активации, $k-$ постоянная Больцмана, $T$ - температура. Первоначально под $\gamma$ подразумевалась величина, численно равная произведению объема, „близкого к атомарному“, на безразмерный коэффициент локального перенапряжения межатомной связи, в частности, в полимерной цепи [53-55]. Однако величине $\gamma$, особенно там, где процессы деформирования могут быть коллективными (дислокационная пластичность, полиморфные превращения и т.д.), можно при- дать и другой смысл. Так, например, при дислокационной пластичности в кристаллических твердых телах величину $\gamma$ можно рассматривать как произведение атомного размера $a$ (или модуля вектора Бюргерса $b$ ) на активационную площадь $S_{a}$, которая ,заметается“ дислокационным сегментом в одном элементарном акте пластической деформации. В этом случае величина $\gamma$ отражает способность структуры реагировать на единичную термическую флуктуацию самоорганизующимся коллективным процессом, охватывающим некоторое количество атомов $N_{a} \sim \gamma / a^{3}$. Такое значение величине $\gamma$, входящей в уравнение Журкова, придавалось в ряде более поздних работ, развивающих кинетическую концепцию прочности и пластичности при одноосном нагружении (см., например, [56-60]) и при индентировании [61-64].

В настоящей работе величина $\gamma$, обусловленная механизмами пластической деформации и динамикой основных ее носителей при наноиндентировании, определялась с помощью соотношения $[47,51,52]$

$$
\gamma=\sqrt{3} \frac{\partial \ln \varepsilon}{\partial \sigma} k T
$$

Некоторые погрешности определения $\gamma$ таким упрощенным способом не имеют принципиального значения для целей нашего рассмотрения, поскольку носители и механизмы пластической деформации различной природы характеризуются разницей в значении $\gamma$ на порядки величин.

Другой полезной характеристикой для определения природы деформации может служить величина удельной энергии образования пластического отпечатка $W$, которая находилась из соотношения

$$
W=U / N,
$$

где $U=\int P d n-$ энергия, рассеиваемая в материале при формировании отпечатка [2,34,35,65-67], определяемая как площадь, ограниченная кривыми нагруженияразгрузки $P-h$-диаграмм, $N=V / V_{i}-$ количество атомов (или ионов) материала, вытесненных из отпечатка, $V=\int_{0}^{h_{c}} S d h$ - объем отпечатка, $S=\frac{\sqrt{3}}{4} d^{2}$ - текущее значение площади проекции отпечатка на поверхности образца, $d$ - сторона отпечатка, $V_{i}$ - объем, приходящийся на один атом (или ион) исследуемого материала.

Анализ зависимостей $\gamma=f\left(h_{\max }\right)$ и $W=f\left(h_{\max }\right)$, приведенных на рис. 5 и 6 , показывает, что в исследованном диапазоне глубин (от $20 \mathrm{~nm}$ до нескольких десятков микрометров) значения величин $\gamma$ для плавленого кварца, поликарбоната, монокристаллического кремния и политетрафторэтилена сначала растут до некоторого критического значения глубины отпечатка $h_{\mathrm{cr}}$, a затем остаются практически постоянными (например, для плавленого кварца $h_{\mathrm{cr}} \approx 100 \mathrm{~nm}$, для поликарбоната $h_{\text {cr }} \approx 200 \mathrm{~nm}$ ). Для сапфира, TZP-керамики, LiF и $\mathrm{Al}$ значения $\gamma$ растут во всем исследованном диапазоне $h$. 
Величина $W$ для всех исследованных материалов сначала растет до некоторого значения $h_{w}$, принимая при этом максимальные значения, а затем начинает уменьшаться с ростом $h$ и выходит на постоянный уровень. При этом для плавленого кварца, поликарбоната и политетрафторэтилена достижение значений $h_{\mathrm{cr}}$, отмечаемое как выход на насыщение величины $\gamma$, соответствует и выходу на постоянные значения величины $W$ (рис. 5 и 6).

Сопоставляя полученные значения $\gamma$ с величиной $b^{3}$, a $W-$ с энергией активации зарождения и перемещения различных структурных дефектов (точечные дефекты, краудионы и малоатомные кластеры, дислокации и др.), можно индентифицировать механизмы
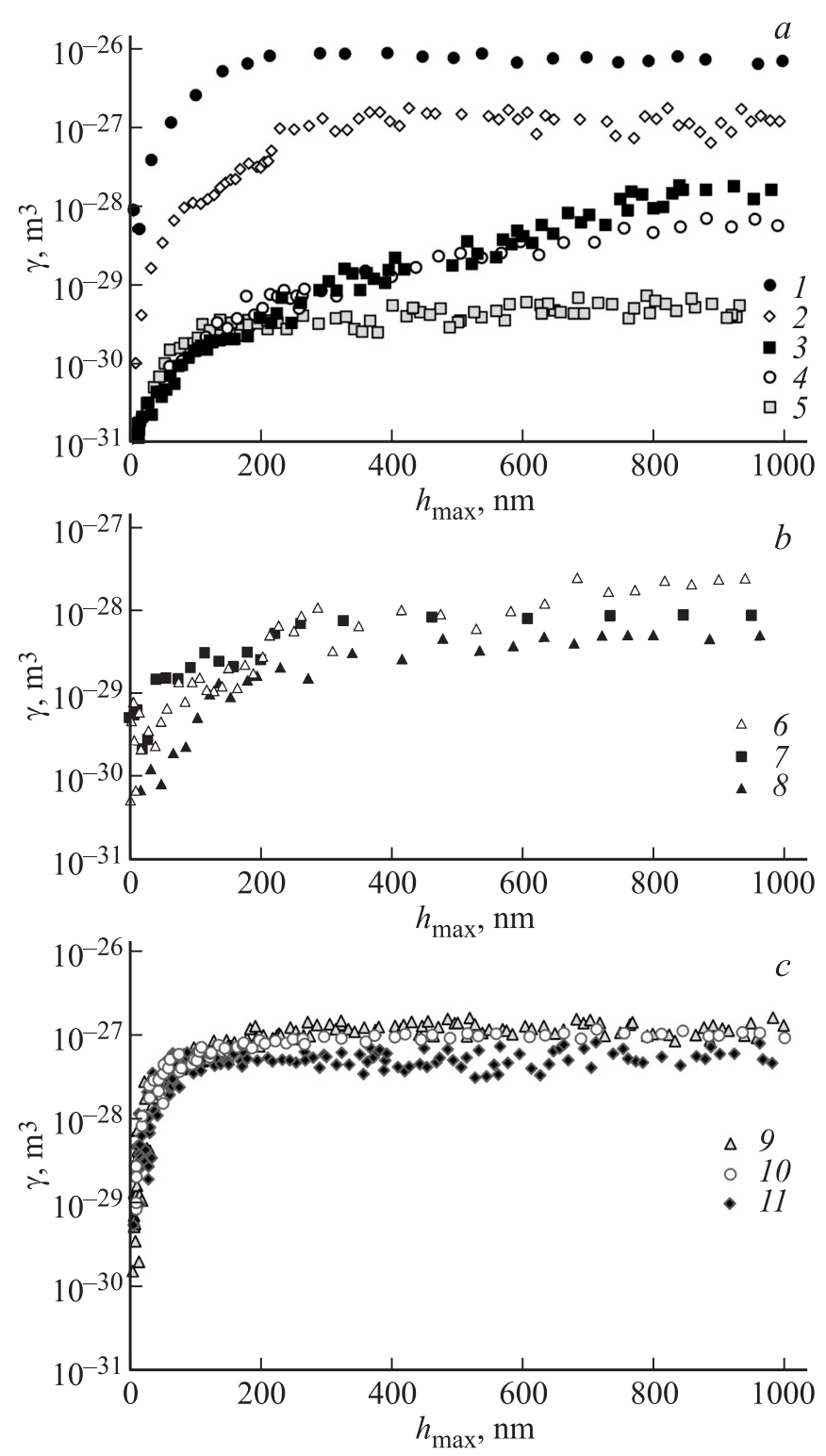

Рис. 5. Зависимость величины активационного объема $\gamma$ от максимальной глубины отпечатка $h_{\max }$. $a-$ политетрафторэтилен (1), поликарбонат (2), сапфир (3), ТZР-керамика (4), плавленый кварц (5); $b-\mathrm{Al}(6), \operatorname{LiF}(7), \mathrm{Si}(8) ; c-\mathrm{Cu}(9)$, $\mathrm{Nb}(10), \mathrm{Ni}(11)$.
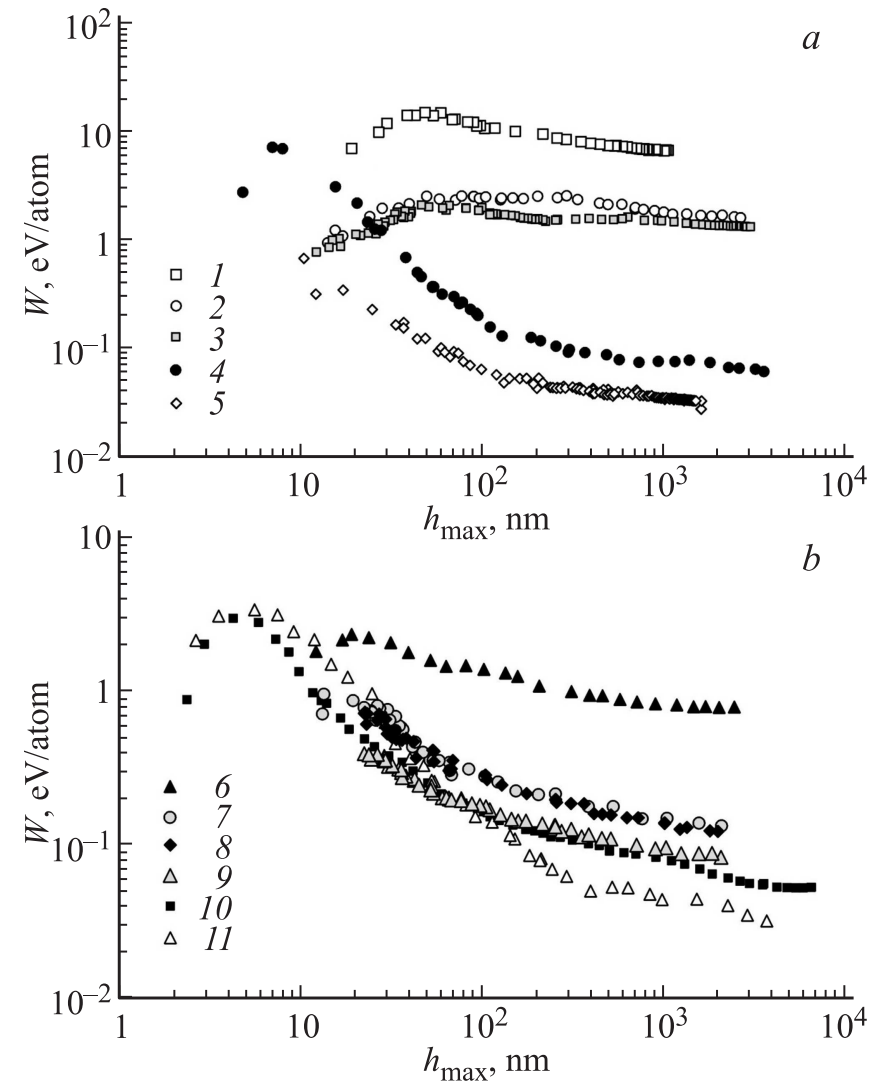

Рис. 6. Зависимость удельной энергии $W$, рассеиваемой при формировании отпечатка, от максимальной глубины отпечатка $h_{\max } . a-$ сапфир (1), TZР-керамика (2), плавленый кварц (3), политетрафторэтилен (4), поликарбонат (5); $b-\mathrm{Si}(6)$, $\mathrm{Nb}$ (7), Ni (8), Cu (9), LiF (10), Al (11).

пластической деформации на разных стадиях формирования отпечатка или, как минимум, отсеять те, которые не согласуются с найденными значениями $\gamma$ и $W$ по порядкам величин. Набор некоторых возможных механизмов пластической деформации в зависимости от величины $b^{3}[38,47,59,68-71]$ схематически представлен на рис. 7.

Значения величин $\gamma$ и $W$, полученные для исследованных материалов в интервале $h_{\max }$ от нескольких десятков нанометров до единиц микрометров (рис. 5 и 6), составляют от $10^{-31}$ до $2 \cdot 10^{-27} \mathrm{~m}^{3}$ и от 0.025 до $10 \mathrm{eV} /$ atom соответственно (в зависимости от типа исследуемого материала и глубины отпечатка). Значение величины $\gamma$ может варьироваться в зависимости от лимитирующего процесса пластической деформации от $\sim b^{3}$ для решеточной диффузии $[47,59,68-71]$ (рис. 7) до $\sim\left(10^{2}-10^{4}\right) b^{3}$ для дислокационных механизмов, например, в ГЦК-металлах $[38,47,68]$ (рис. 5, с и 7). Для энергии активации процессов пластической деформации значения порядка сотых-десятых долей $\mathrm{eV}$ характерны для дислокационных механизмов, а в интервале $1-10 \mathrm{eV}$ сопоставимы с энергией образования точечных дефектов в решетке. Так, например, в работах $[70,71]$ показано, 


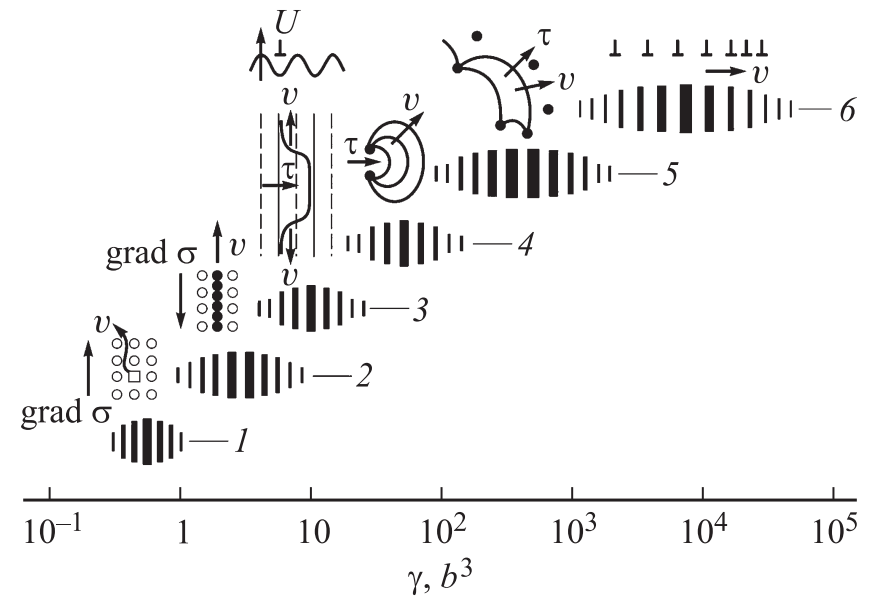

Рис. 7. Схема взаимосвязи наиболее эффективных механизмов пластической деформации с величиной активационного объема $\gamma(b-$ вектор Бюргерса, $\tau$ и $\sigma-$ приложенные напряжения, $v-$ скорость носителя деформации). 1 - ползучесть Кобла (образование и движение неравновесных точечных дефектов), 2 - образование и движение краудионов (по Инденбому-Орлову), 3 - образование и расширение кинков в рельефе Пайерлса, 4 - срабатывание источников дислокаций (по Франку-Риду), 5 - преодоление дислокациями сетки локальных стопоров (по Гилману), 6 - коллективные процессы в дислокационных ансамблях (полосы скольжения, двойники).

что энергия образования кислородной вакансии для $\mathrm{Al}_{2} \mathrm{O}_{3}$ составляет $10.28 \mathrm{eV}$, а для вакансии алюминия $15.49 \mathrm{eV}$ [71].

Низкие значения $\gamma$, составляющие $\sim b^{3}$ (для кристаллических материалов) и порядка нескольких атомарных объемов (для аморфных и полимерных материалов), и высокие значения $W$ (от нескольких десятых долей до единиц $\mathrm{eV} /$ atom), полученные на начальных стадиях формирования отпечатка, характерны для монои/или малоатомных механизмов локального деформирования $[24,25,47,50-52,59,68,70,71]$. Учитывая, что исследованная керамика является наноструктурированной (с размером зерен около $100 \mathrm{~nm}$ ), можно предположить, что ее деформирование может происходить за счет моно- или малоатомных микромеханизмов массопереноса или фазовых переходов метастабильной тетрагональной фазы в стабильную моноклинную. Для плавленого кварца, имеющего аморфную структуру, и сапфира, имеющего кристаллическую структуру, найденные значения величин $\gamma$ и $W$ практически совпадают с данными, полученными для энергии образования точечных структурных дефектов [70,71], что дает основание предполагать определяющую роль моно- или малоатомных механизмов деформации.

Выход на насыщение величин $\gamma$ и $W$ при глубинах отпечатка выше некоторого критического значения, характерного для каждого исследованного материала (рис. 4 и 5), может означать начало установившегося доминирующего процесса пластической деформации материала под индентором. На этом участке высокие значения величин $\gamma$ и низкие для $W$, полученные для ряда исследованных материалов $(\mathrm{LiF}, \mathrm{Al}$, поликарбонат и политетрафторэтилен), свидетельствуют в пользу многоатомных микромеханизмов пластичности. И для LiF, и для $\mathrm{Al}$ они согласуются со значениями, характерными для дислокационного течения.

На особенности деформирования, наличие ISE и механизмы пластичности под индентором могут влиять не только энергетические, но и чисто геометрические и структурные факторы. Так, например, в кристаллических материалах до тех пор, пока глубина погружения и соответственно характерный размер локально нагруженной области не превышают критического радиуса дислокационной петли, дислокации не могут зарождаться гомогенно [4]. Вероятность гетерогенного зарождения дислокаций в объемах $\lesssim 10^{3} b^{3}$ тоже очень мала. В ряде других материалов, например в аморфных, дислокации вообще теряют смысл, так как изначально в них нет кристаллической упорядоченности, которую они могут нарушать.

Для учета возможного влияния местных неоднородностей на величину твердости исследуемого материала были проведены эксперименты в различных точках поверхности исследуемого образца, а также на различных образцах, подготовленных из одного и того же материала. В качестве меры оценки локальной неоднородности свойств материала использовался коэффициент вариации, который определялся как $V_{H}=S_{H} / \bar{H}$. Здесь $S_{H}$ - стандартное отклонение измерений твердости, проведенных по стандартам [34,35], $\bar{H}-$ среднее значение твердости. Из данных для $V_{H}$, полученных для ряда исследованных материалов при фиксированных значениях $P_{\max }$ и $h_{\max }$ (рис. 8 ), следует, что величина $V_{H}$ сильно зависит от типа материала и величины нагрузки, прикладываемой к индентору. При этом увеличение $P_{\max }$ в диапазоне от $10 \mu \mathrm{N}$ до $1 \mathrm{~N}$, как правило, приводит к уменьшению величины $V_{H}$.

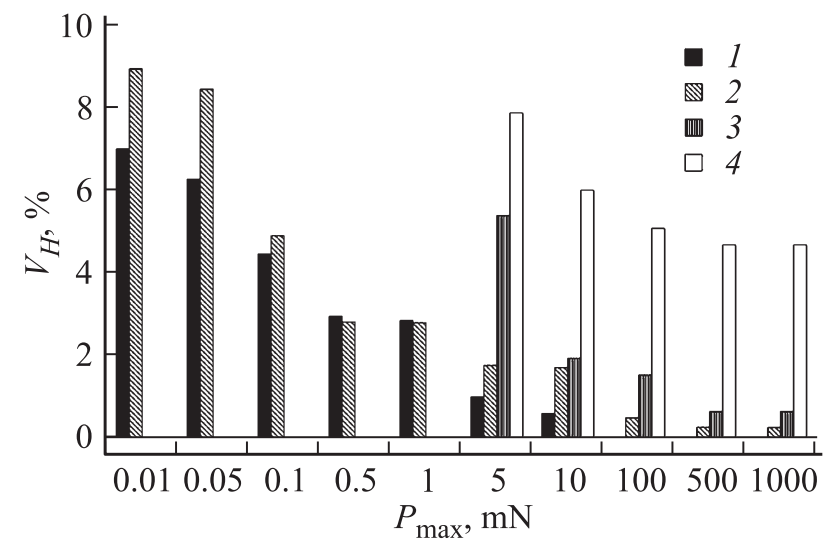

Рис. 8. Зависимость коэффициента вариации $V_{H}$ твердости по Мартенсу от максимальной нагрузки, приложенной к индентору $P_{\max } .1$ - поликарбонат, 2 - плавленый кварц, 3 - сапфир, 4 - ТZР-керамика. 
Так, например, для плавленого кварца и поликарбоната при $P_{\max }$ в интервале от 10 до $50 \mu \mathrm{N}$ коэффициент вариации превышает $8 \%$, в интервале от 100 до $500 \mu \mathrm{N}$ он меньше $5 \%$, в интервале от $500 \mu \mathrm{N}$ до $1 \mathrm{mN}-$ меньше $3 \%$, а в интервале от $5 \mathrm{mN}$ до $1 \mathrm{~N}$ - меньше $2 \%$.

Для ТZР-керамики $V_{H}$ при $P_{\max }=5 \mathrm{mN}$ превышает $8 \%$, с ростом нагрузки $V_{H}$ уменьшается и при $P_{\max }=1 \mathrm{~N}$ составляет $5 \%$. Для сапфира при $P_{\max }=5 \mathrm{mN}$ коэффициент вариации более $5 \%$, а при $P_{\max } \geq 10 \mathrm{mN}$ он падает до значений $\leq 2 \%$.

Таким образом, плавленый кварц и поликарбонат наряду с постоянным значением твердости имеют коэффициент вариации менее 5\% в диапазоне нагрузок от $100 \mu \mathrm{N}$ до $1 \mathrm{~N}$, а сапфир - при $P_{\max } \geq 10 \mathrm{mN}$. Такие значения полностью соответствуют требованиям стандартов ГОСТ и ISO $[34,35]$, и поэтому эти материалы (в установленных диапазонах нагрузок) являются хорошими кандидатами для использования в качестве мер твердости и эталонов, предназначенных для обеспечения единства измерений в нано- и микродиапазонах глубины отпечатка, а также для проведения калибровок и испытаний наноиндентометров.

\section{4. Заключение}

В широком диапазоне глубин отпечатка (от $20 \mathrm{~nm}$ до десятков микрометров) в работе выявлены зависимости твердости ряда репрезентативных представителей материалов различных классов: ионных и ковалентных монокристаллов (сапфира, кремния, фторида лития); металлов (монокристаллического $\mathrm{Al}$, поликристаллических $\mathrm{Cu}, \mathrm{Ni}, \mathrm{Nb}$ ); керамик (высокопрочной наноструктурированной ТZР-керамики на основе природного минерала диоксида циркония - бадделеита); аморфных материалов (плавленого кварца); полимеров (поликарбоната и политетрафторэтилена).

Погружение индентора от момента касания поверхности и до образования отпечатка размером до нескольких микрометров в мягких металлах происходит в несколько стадий. Низкие значения $\gamma$ и высокие значения $W$ в области малых глубин отпечатка $h<h_{\text {cr }}$ свидетельствуют в пользу того, что дислокационные механизмы не могут играть доминирующей роли в пластическом течении исследуемых материалов на начальной стадии локального деформирования острым индентором. Более вероятными представляются недислокационные механизмы деформации, в частности реализуемые путем образования и перемещения неравновесных точечных дефектов и их небольших скоплений - краудионов. При этом твердость ряда исследованных материалов сначала нарастает с увеличением глубины отпечатка, а затем падает, поскольку включаются более эффективные механизмы пластической деформации, а именно дислокационного течения. По мере увеличения размеров отпечатка исследуемые материалы демонстрируют два типа поведения и могут быть разделены на два класса: материалы, не имеющие ISE (плавленый кварц, поликарбонат, сапфир и политетрафторэтилен), и материалы, в которых твердость начинает падать с ростом $h$ (ТZР-керамика, $\mathrm{LiF}, \mathrm{Al}, \mathrm{Cu}, \mathrm{Nb}, \mathrm{Ni}$ и др.). Уменьшение твердости с ростом размера отпечатка в материалах второй группы сопровождается ростом значений $\gamma$ и уменьшением $W$, значения которых дают основание полагать, что роль многоатомных (например, дислокационных) механизмов пластичности нарастает, а недислокационных падает при увеличении размеров области локальной деформации.

Отсутствие ISE в ряде исследованных материалов или участки с постоянными значениями твердости для материалов, имеющих ISE (в области больших размеров отпечатка), характеризуются постоянными значениями величин $\gamma$ и $W$, что свидетельствует о неизменном доминирующем механизме пластической деформации. Такое поведение характерно, например, для плавленого кварца и поликарбоната.

Низкие значения коэффициента вариации твердости $\left(V_{H}<5 \%\right.$ при $P_{\max } \geq 100 \mu \mathrm{N}$ для плавленого кварца и при $P_{\max } \geq 10 \mathrm{mN}$ для сапфира) полностью соответствуют требованиям стандартов ГОСТ и ISO [34,35] и поэтому данные материалы (в установленных диапазонах нагрузок) являются хорошими кандидатами для использования в качестве мер и эталонов твердости для обеспечения единства измерений механических свойств твердых тел в нано- и микродиапазонах глубины отпечатка, а также для проведения калибровки, юстировки и настройки наноиндентометров.

\section{Список литературы}

[1] Springer handbook of nanotechnology / Ed. B. Bhushan. Springer-Verlag, Berlin (2010). 1968 p.

[2] Ю.И. Головин. Основы нанотехнологий. Машиностроение, М. (2012). $656 \mathrm{c}$.

[3] A.C. Fischer-Cripps. Nanoindentation. Springer, N.Y. (2011). $279 \mathrm{p}$.

[4] Ю.И. Головин. Наноиндентирование и его возможности. Машиностроение, М. (2009). 312 с.

[5] А.С. Гращенко, С.А. Кукушкин, А.В. Осипов. Письма в ЖТФ 40, 24, 53 (2014).

[6] W.D. Nix, H. Gao. J. Mech. Phys. Solids 46, 411 (1998).

[7] L.A. Berla, S.W. Lee, Yi. Cui, W.D. Nix. J. Power Sources 273, 41 (2015).

[8] X. Qiao, L. Han, W. Zhang, J. Gu. Mater. Characterization 110, 86 (2015).

[9] T. Csanádi, S. Grasso, A. Kovalcíková, J. Dusza, M. Reece. J. Eur. Ceram. Soc. 36, 239 (2016).

[10] D. Wu, J.S.C. Jang, T.G. Nieh. Intermetallics 68, 118 (2016).

[11] Ю.И. Головин. ФТТ 50, 2113 (2008).

[12] Ю.И. Головин, В.М. Васюков, В.В. Коренков, Р.А. Столяров, А.В. Шуклинов, Л.Е. Поляков. ЖТФ 81, 5, 55 (2011).

[13] Ю.И. Головин, В.И. Иволгин, А.И. Тюрин, С.В. Потапов, В.3. Бенгус, Е.Д. Табачникова. Кристаллография 50, 326 (2005). 
[14] М.Ш. Акчурин, Р.В. Гайнутдинов, Е.А. Гарибин, Ю.И. Головин, А.А. Демиденко, К.В. Дукельский, С.В. Кузнецов, И.А. Миронов, В.В. Осико, А.Н. Смирнов, Н.Ю. Табачкова, А.И. Тюрин, П.П. Федоров, В.В. Шиндяпин. Перспективные материалы 5, 5 (2010).

[15] W.C. Oliver, G.M. Pharr. J. Mater. Res. 7, 1564 (1992).

[16] W.C. Oliver, G.M. Pharr. J. Mater. Res. 19, 3 (2004).

[17] D.M. Dimiduk, M.D. Uchic, T.A. Parthasarathy. Acta Mater. 53, 4065 (2005).

[18] J. Biener, A.M. Hodge, J.R. Hayes, C.A. Volkert, L.A. ZepedaRuiz, Al.V. Hamza, F.F. Abraham. Nanoletters 6, 2379 (2006).

[19] F. Xu, Y.H. Ding, X.H. Deng, P. Zhang, Z.L. Long. Physica B 450, 84 (2014).

[20] D. Maharaj, B. Bhushan. Mater. Sci. Eng. R 95, 1 (2015).

[21] K. Herrmann, N.M. Jennett, S. Kuypers, I. McEntegaart, C. Ingelbrecht, U. Hangen, T. Chudoba, F. Pohlenz, F. Menelaoa. Z. Metallk. 94, 802 (2003).

[22] Hardness testing: principles and applications / Ed. K. Herrmann. ASM International, Materials Park, Ohio (2011). 258 p.

[23] Ю.И. Головин, А.И. Тюрин, В.В. Хлебников. ЖТФ 75, 4, 91 (2005).

[24] Yu.I. Golovin, A.I. Tyurin, B.Ya. Farber. Phil. Mag. A 82, 1857 (2002).

[25] Yu.I. Golovin, A.I. Tyurin, B.Ya. Farber. J. Mater. Sci. 37, 895 (2002).

[26] Ю.И. Головин, В.И. Иволгин, А.И. Тюрин, В.А. Хоник. ФТT 45, 1209 (2003).

[27] Ю.И. Головин, А.А. Шибков, Ю.С. Боярская, М.С. Кац, А.И. Тюрин. ФТТ 30, 3491 (1988).

[28] С.Д. Викторов, Ю.И. Головин, А.Н. Кочанов, А.И. Тюрин, А.В. Шуклинов, И.А. Шуварин, Т.С. Пирожкова. Физ.-техн. пробл. разработки полезных ископаемых 50, 46 (2014).

[29] Ю.И. Головин, Р.Б. Моргунов, Д.В. Лопатин, А.А. Баскаков, Я.Е. Евгеньев. ФТТ 40, 2065 (1998).

[30] Ю.И. Головин, Р.Б. Моргунов. ФТТ 43, 827 (2001).

[31] Ю.А. Осипьян, Ю.И. Головин, Р.Б. Моргунов, Р.К. Николаев, И.А. Пушнин, С.3. Шмурак. ФТТ 43, 1333 (2001).

[32] Yu. Golovin, R. Morgunov, A. Baskakov. Mol. Phys. 100, 1291 (2002).

[33] Ю.И. Головин, Р.Б. Моргунов. Письма в ЖЭТФ 61, 583 (1995).

[34] ГОСТ Р 8.748-2011. Металлы и сплавы. Измерение твердости и других характеристик материалов при инструментальном индентировании. Ч. 1. Метод испытаний. Стандартинформ, М. (2013). 24 с.

[35] ISO 14577-1 to 3 (2002), ISO 14577-4 (2007): Metallic materials - instrumented indentation test for hardness and materials parameters. Parts 1-4.

[36] X. Feng, Y. Hyang, K. Hwang. In: Micro- and nano mechnical testing of materials and devices / Eds F. Yang, J.C.M. Li. Springer, N.Y. (2008). P. 49.

[37] Ю.Р. Колобов Диффузионно-контролируемые процессы на границах зерен и пластичность металлических поликристаллов. Наука, Новосибирск (1998). 184 с.

[38] Р.А. Андриевский, А.М. Глезер. УФН 179, 337 (2009).

[39] Y.Y. Lim, M.M. Chaudhri. Phil. Mag. A 82, 2071 (2002).

[40] I. Manika, J. Maniks. Acta Mater. 54, 2049 (2006).

[41] S. Qu, Y. Huang, W.D. Nix, H. Jiang, F. Zhang, K.C. Hwang. J. Mater. Res. 19, 3423 (2004).

[42] M.A. Meyers, A. Mishra, D.J. Benson. Prog. Mater. Sci. 51, 427 (2006).
[43] T.P. Remington, C.J. Ruestes, E.M. Bringa, B.A. Remington, C.H. Lu, B. Kad, M.A. Meyers. Acta Mater. 78, 378 (2014).

[44] C.J. Ruestes, A. Stukowski, Y. Tang, D.R. Tramontina, P. Erhart, B.A. Remington, H.M. Urbassek, M.A. Meyers, E.M. Bringa. Mater. Sci. Eng. A 613, 390 (2014).

[45] A.E. Romanov, A.L. Kolesnikova, I.A. Ovid'ko, E.C. Aifantis. Mater. Sci. Eng. A 503, 62 (2009).

[46] В.Л. Инденбом. Письма в ЖЭТФ 12, 526 (1970).

[47] I.C. Choi, Y.J. Kim, B. Ahn, M. Kawasaki, T.G. Langdon, J.I. Jang. Scripta Mater. 75, 102 (2014).

[48] Ю.И. Головин, С.Н. Дуб, В.И. Иволгин, В.В. Коренков, А.И. Тюрин. ФТТ 47, 961 (2005).

[49] Ю.И. Головин, В.И. Иволгин, В.В. Коренков, А.И. Тюрин. Письма в ЖТФ 23, 15 (1997).

[50] Ю.И. Головин, А.И. Тюрин. Изв. РАН. Сер. физ. 59, 49 (1995).

[51] Ю.И. Головин, А.И. Тюрин. ФТТ 38, 1812 (1996).

[52] Ю.И. Головин, А.И. Тюрин. Кристаллография 40, 884 (1995).

[53] С.Н. Журков, Б.Н. Нарзуллаев. ЖТФ 23, 1677 (1953).

[54] S.N. Zhurkov. International J. Fracture Mech. 1, 311 (1965).

[55] В.Р. Регель, А.И. Слуцкер, Э.Е. Томашевский. Кинетическая природа прочности твердых тел. Физматлит, М. (1974). $560 \mathrm{c}$.

[56] В.Л. Инденбом, А.Н. Орлов. В кн.: Термически активируемые процессы. Мир, М. (1973). С. 5.

[57] В.Л. Инденбом, А.Н. Орлов, Ю.З. Эстрин. В кн.: Элементарные процессы пластической деформации кристаллов. Наук. думка, Киев (1978). С. 93.

[58] В.Л. Гиляров. ФТТ 47, 808 (2005).

[59] H. Conrad. Nanotechnology 18, 325701 (2007).

[60] L. Lu, X. Chen, X. Huang, K. Lu. Science 323, 607 (2009).

[61] H. Somekawa, A. Singh, C.A. Schuh. J. Alloys Compd. 685, 1016 (2016).

[62] H. Somekawa, C.A. Schuh. Acta Mater. 59, 7554 (2011).

[63] J.K. Mason, A.C. Lund, C.A. Schuh. Phys. Rev. B 73, 054102 (2006).

[64] C.A. Schuh, J.K. Mason, A.C. Lund. Nature Mater. 4, 617 (2005).

[65] M. Sakai. Acta Met. Mater. 41, 1751 (1993).

[66] M.T. Attaf. Mater. Lett. 57, 4684 (2003).

[67] O. Uzun, N. Güçlü, U. Kölemen, O. Şahin. Mater. Chem. Phys. 112, 5 (2008).

[68] H. Conrad. Mater. Sci. Eng. A 341, 216 (2003).

[69] H.J. Frost, M.F. Ashby. Deformation mechanism maps: the plasticity and creep of metals and ceramics. Pergamon Press, Oxford (1982). $165 \mathrm{p}$.

[70] С.В. Еремеев, Л.Ю. Немирович-Данченко, С.Е. Кулькова. ФTT 50, 523 (2008).

[71] J. Carrasco, N. Lopez, F. Illas. Phys. Rev. Lett. 93, 225502 (2004). 